\title{
Emotional status: diagnosis and treatment for severe psychiatric disorders
}

\author{
P. Falkai · H.-J. Möller
}

Published online: 28 December 2011

(C) The Author(s) 2011. This article is published with open access at Springerlink.com

This edition focuses on the emotional status that is affected in a variety of psychiatric disorders, ranging from affective disorders to schizophrenia and patients with drug abuse.

In patients with major depressive disorders, hypomania is a common cluster of symptoms that is derived from diagnostic DSM-IV criteria. To assess the clinical validity of these criteria in an international sample, Angst et al. [1] analyzed clinical data including family history, course, and clinical characteristics in 5,635 patients with major depressive episodes. Items for hypomania, irritability, elevated mood, and increased activity could be shown to be valid and confirm symptom threshold in DSM-IV. However, brief hypomanic episodes over only a few days were also valid for which reason DSM-IV durational requirements should be altered. Additionally, exclusion criteria like hypomania due to antidepressant treatment should be revised in the face of the exclusion of patients with bipolar disorder. During the last years, the usage of antidepressants in treating acute depression and its efficacy were under debate. In a review of randomized clinical trials and metaanalyses, Baghai et al. [2] summarize methodological issues of these studies and confirm efficacy and clinical effectiveness of antidepressants in the treatment of depressive disorder. Additionally, they allocate individualized antidepressant treatment to be safe and well tolerated in most patients and assert that it should be combined with psychotherapy.

\section{P. Falkai $(\bowtie)$}

Department of Psychiatry and Psychotherapy, University of Göttingen, Von-Siebold-Str. 5, 37075 Göttingen, Germany e-mail: pfalkai@gwdg.de

H.-J. Möller

Psychiatry Hospital, Ludwigs-Maximililans-University Munich, Nussbaumstr. 7, 80336 Munich, Germany
In patients with affective disorders and schizophrenia, improved diagnostic criteria are needed and might be developed by neuroimaging tools. A glutamate hypothesis has been linked to both syndromes, and the application of modern magnetic resonance spectroscopy (MRS) may elucidate the relationship between risk genes and the glutamate system as a first step in the development of a more personalized medicine. Gruber et al. [3] investigated brain-derived neurotrophic factor (BDNF) polymorphisms and MRS in a sample of 103 patients with schizophrenia, bipolar disorder, and healthy controls. Independently of diagnosis, in the left hippocampus, they found homozygous met-allele carriers exhibiting lower NAA/Cre and (Glu + Gln)/Cre metabolic ratios compared with val/val homozygotes. Alterations in BDNF have been hypothesized to be related to disturbed synaptic plasticity in psychiatric diseases, and this study is the first of its kind to show associations with the glutamate system. A MRS study by Wang et al. [4] revealed the relationship between higher $\mathrm{Glu} / \mathrm{Cr}$ ratio and post-stroke depression in the frontal lobe, thus according to the hypothesis of increased glutamate activity in depression.

Suicide is the most severe complication in psychiatric diseases. During the last years, the internet verifiably has served as a platform for suicide attempters. Hagihara et al. [5] found an association between internet suicide-related searches and the incidence of suicide in Japan during a period of 77 months. Correspondingly, the authors claim a stricter regulation of internet suicide websites.

Emotional responses are not only altered in patients with affective disorders, but also in cannabis users with a negative emotional state. Somaini et al. [6] compared fourteen active marijuana smokers and fourteen marijuana-dependent patients abstinent for a period of 6 months with healthy controls. In a self-assessment, active cannabis users had higher scores of pleasant emotions and lower arousal levels 
along with hyperactivity of the HPA axis with an impaired hormonal reaction to negative emotions. The study shows a reduced sensitivity to negative emotions and HPA axis dysfunction in active cannabis users. In contrast, in patients with paranoid schizophrenia, Haralanova et al. [7] found higher subjective emotional arousal evoked by neutral social stimuli, contributing to the paranoid symptom complex of schizophrenia. This maybe represents a clinical phenotype linked to underlying neurobiological disturbances.

The molecular basis of repetitive transcranial magnetic stimulation (rTMS), which is a novel technique for brain stimulation and a novel therapeutic tool in psychiatric diseases, has been investigated by Hellmann et al. [8]. The group detected increased cyclic adenosine monophosphate (cAMP) levels and phosphorylation of the transcription factor cAMP response element-binding protein (CREB) in human-derived neuroblastoma cell culture in response to rTMS. Interestingly, pretreatment with ketamine potentiated the response, thus confirming the role of ketamine on electroconvulsive therapy in clinical studies. From animal studies, it is well known that cAMP signaling within neurons plays an important role in depression and antidepressant treatment. In the hippocampus, CREB-regulated gene transcription promotes dendritic sprouting and neurogenesis. There is a need of investigations on the molecular basis of modern treatment approaches in psychiatric diseases aiming at the development of regenerative treatment strategies in favor of improving their outcome.

Open Access This article is distributed under the terms of the Creative Commons Attribution Noncommercial License which permits any noncommercial use, distribution, and reproduction in any medium, provided the original author(s) and source are credited.

\section{References}

1. Angst J, Gamma A, Bowden CL, Azorin JM, Perugi G, Vieta E, Young AH (2011) Diagnostic criteria for bipolarity based on an international sample of 5,635 patients with DSM-IV major depressive episodes. Eur Arch Psychiatry Clin Neurosci. doi: 10.1007/s00406-011-0228-0

2. Baghai TC, Blier P, Baldwin DS, Bauer M, Goodwin GM, Fountoulakis KN, Kasper S, Leonard BE, Malt UF, Stein DJ, Versiani M, Möller H-J (2011) Executive summary of the report by the WPA section on pharmacopsychiatry on general and comparative efficacy and effectiveness of antidepressants in the acute treatment of depressive disorders. Eur Arch Psychiatry Clin Neurosci. doi:10.1007/s00406-011-0274-7

3. Gruber O, Hasan A, Scherk H, Wobrock T, Schneider-Axmann T, Ekawardhani S, Schmitt A, Backens M, Reith W, Meyer J, Falkai $P$ (2011) Association of the brain-derived neurotrophic factor val66met polymorphism with magnetic resonance spectroscopic markers in the human hippocampus: in vivo evidence for effects on the glutamate system. Eur Arch Psychiatry Clin Neurosci. doi: 10.1007/s00406-011-0214-6

4. Wang X, Li Y-H, J Lu, M-H Li, Zhao J-G, Sun X-J, Zhang B, Ye J-L (2011) Glutamate level detection by magnetic resonance spectroscopy in patients with post-stroke depression. Eur Arch Psychiatry Clin Neurosci. doi:10.1007/s00406-011-0209-3

5. Hagihara A, Miyazaki S, Abe T (2011) Internet suicide searches and the incidence of suicide in young people in Japan. Eur Arch Psychiatry Clin Neurosci. doi:10.1007/s00406-011-0212-8

6. Somaini L, Manfredini M, Amore M, Zaimovic A, Raggi MA, Leonardi C,Gerra ML, Donnini C, Gerra G (2011) Psychobiological responses to unpleasant emotions in cannabis users. Eur Arch Psychiatry Clin Neurosci. doi:10.1007/s00406-0110223-5

7. Haralanova E, Haralanov S, Beraldi A, Möller H-J, Hennig-Fast K (2011) Subjective emotional over-arousal to neutral social scenes in paranoid schizophrenia. Eur Arch Psychiatry Clin Neurosci. doi: 10.1007/s00406-011-0227-1

8. Hellmann J, Jüttner R, Roth C, Bajbouj M, Kirste I, Heuser I, Gertz K, Endres M, Kronenberg G (2011) Repetitive magnetic stimulation of human-derived neuron-like cells activates cAMPCREB pathway. Eur Arch Psychiatry Clin Neurosci. doi: 10.1007/s00406-011-0217-3 